\title{
Variations in DNA methylation of interferon gamma and programmed death 1 in allograft rejection after kidney transplantation
}

Karin Boer ${ }^{1 *}$, L. Elly A. de Wit ${ }^{1}$, Fleur S. Peters ${ }^{1}$, Dennis A. Hesselink¹, Leo J. Hofland², Michiel G. H. Betjes ${ }^{1}$, Caspar W. N. Looman ${ }^{3}$ and Carla C. Baan ${ }^{1}$

\begin{abstract}
Background: The role of DNA methylation in the regulation of the anti-donor-directed immune response after organ transplantation is unknown. Here, we studied the methylation of two mediators of the immune response: the pro-inflammatory cytokine interferon $y$ (IFNY) and the inhibitory receptor programmed death 1 (PD1) in naïve and memory CD8+ T cell subsets in kidney transplant recipients receiving immunosuppressive medication. Both recipients experiencing an episode of acute allograft rejection (rejectors) as well as recipients without rejection (non-rejectors) were included.

Results: CpGs in the promoter regions of both IFNY and PD1 were significantly $(p<0.001)$ higher methylated in the naïve CD8+ T cells compared to the memory $T$ cell subsets. The methylation status of both IFNY and PD1 inversely correlated with the percentage of IFNy or PD1-producing cells. Before transplantation, the methylation status of both IFNY and PD1 was not significantly different from healthy donors. At 3 months after transplantation, irrespective of rejection and subsequent anti-rejection therapy, the IFNy methylation was significantly higher in the differentiated effector memory CD45RA+ (EMRA) CD8+T cells $(p=0.01)$ whereas the PD1 methylation was significantly higher in all memory CD8+ T cell subsets (CD27+ memory; $p=0.02$ : CD27- memory; $p=0.02$ : EMRA; $p=0.002$ ). Comparing the increase in methylation in the first 3 months after transplantation between rejectors and non-rejectors demonstrated a significantly more prominent increase in the PD1 methylation in the CD27- memory CD8+ T cells in rejectors (increase in rejectors $14 \%$, increase in non-rejectors $1.9 \%, p=0.04$ ). The increase in DNA methylation in the other memory CD8+ T cells was not significantly different between rejectors and non-rejectors. At 12 months after transplantation, the methylation of both IFNY and PD1 returned to baseline levels.
\end{abstract}

Conclusions: The DNA methylation of both IFNY and PD1 increases the first 3 months after transplantation in memory CD8+ T cells in kidney transplant recipients. This increase was irrespective of a rejection episode indicating that general factors of the kidney transplantation procedure, including the use of immunosuppressive medication, contribute to these variations in DNA methylation.

Keywords: DNA methylation, CD8 T-cell subset, IFNy, PD1, Kidney transplant recipients, Allograft rejection

\footnotetext{
* Correspondence: karin.boer@erasmusmc.nl

1Department of Internal Medicine, Section Nephrology and Transplantation,

Erasmus MC, University Medical Center Rotterdam, Room Na520, P.O. Box

20403000 CA Rotterdam, The Netherlands

Full list of author information is available at the end of the article
} 


\section{Background}

Kidney transplantation is currently the best treatment option for patients with irreversible, end-stage kidney disease [1]. Successful kidney transplantation is hampered by different complications including immune-mediated complications such as acute rejection [2]. Several noninvasive biomarkers for acute rejection have been studied, including proteins involved in cytotoxic lymphocyte function (e.g., perforin and granzyme B), cytokines (e.g., interferon (IFN) $\gamma$ ), and immune-related chemokines (e.g., CXCL9 and CXCL10) [3, 4]. Nevertheless, it remains difficult to predict and regulate the host immune response after transplantation. The host immune response is orchestrated by a tightly regulated cascade of gene expression changes which are regulated by epigenetic mechanisms like histone modifications, DNA methylation, microRNA interactions, and chromatin remodeling complexes [5-8]. Variations in these epigenetic mechanisms might serve as an additional marker to monitor the host immune response after organ transplantation.

An important player of the host immune response is the pro-inflammatory cytokine IFN $\gamma$, and high expression of IFN $\gamma$ is associated with both acute and chronic allograft rejection [9-11]. The expression of IFN $\gamma$ is regulated by DNA methylation with the addition of methyl groups on cytosine-phosphate-guanine sites (CpGs) in the $I F N \gamma$ promoter region silencing its expression. The CpG methylation pattern of IFNy discriminates different $\mathrm{T}$ cell subsets. First, naïve (antigen unexperienced) $\mathrm{T}$ cells versus memory (antigen experienced) T cells (both CD4+ and CD8+ T cells) with memory $\mathrm{T}$ cells having a lower methylation profile [12-14]. Second, the different $\mathrm{T}$ helper cell (Th) subsets with Th1 cells being hypomethylated compared to the Th2 and Th17 subsets [15-17]. Another important molecule involved in the regulation of the antidonor immune response is the inhibitory receptor programmed cell death (PD) 1. Aggressive recipient T cells that attack the transplanted organ, the so-called alloreactive $\mathrm{T}$ cells, are inhibited by PD1 signaling. In addition, PD1 signaling promotes the generation of induced regulatory $\mathrm{T}$ cells $[18,19]$. The expression of $P D 1$ is also dependent on DNA methylation and while mainly methylated in naïve T cells, PD1 is demethylated during differentiation into memory T cells [20].

Regulation of gene expression by DNA methylation is a well-known epigenetic mechanism with a critical role in physiological development and normal cell function by coordinating the lineage- and tissue-specific expression of genes [21]. DNA methylation is dynamic and susceptible to stimuli from the environment including internal stimuli like cytokines and hormones and external stimuli like chemical agents, pollutants, dietary components, and chronic viral infections [16, 22-24]. Aberrant DNA methylation profiles are associated with the pathogenesis of disease. Initially, DNA methylation was associated with tumor formation and progression [25], but later on, variations in DNA methylation have been associated with other diseases [26, 27] including chronic kidney disease (CKD) [28, 29] and immunemediated diseases such as rheumatoid arthritis [30] and allergy [31, 32]. In addition, variations in DNA methylation of immune-related genes orchestrate the host immune response after organ transplantation [5-8].

Graft-infiltrating cytotoxic CD8+ T cells play a major role in the rejection process and elevated numbers of effector, and memory CD8+ T cell subsets are associated with an increased risk for acute rejection [33-35]. Here, we examined the influence of variations in DNA methylation of $I F N \gamma$ and $P D 1$ in different CD8+ T cell subsets on allograft rejection. The DNA methylation of IFN $\gamma$ and $P D 1$ was determined in kidney transplant recipients before and 3 and 12 months after transplantation, and both kidney transplant recipients who experienced a rejection episode within the first 3 months after transplantation and recipients who remained free from rejection were included. To exclude gender- [32] or chronic viral infection [24]-related differences, we first analyzed whether the DNA methylation of either IFN $\gamma$ or PD1 was different in males versus females or in cytomegalovirus (CMV) seropositive healthy donors versus CMV seronegative healthy donors.

\section{Results \\ IFNy methylation is significantly decreased in CMV seropositive individuals}

In PBMCs of CMV seronegative healthy donors, the DNA methylation of IFNy was $51.2 \pm 4.4 \%$ (mean \pm SD). The IFNy methylation was significantly lower in PBMCs of age-matched CMV seropositive healthy kidney donors (45.1 $\pm 7.2 \%, p=0.009$; Fig. 1a). In both males and females, the methylation of IFNy was lower in the CMV seropositive individuals (Fig. 1a), and there was no significant difference between males and females. The DNA methylation of PD1 in PBMCs of CMV seronegative healthy donors was comparable to the PD1 methylation in CMV seropositive healthy donors ( $40.5 \pm 5.3$ versus $38.9 \pm 6.3 \%$; Fig. 1 b). Subdividing the PBMCs into the different CD8+ T cell subsets (Fig. 1c) demonstrated significantly lower methylation of IFN $\gamma$ in naïve, CD27+ memory, and CD27- memory CD8+ $\mathrm{T}$ cells in CMV seropositive individuals compared to CMV seronegative individuals (Fig. 1d). The methylation of PD1 was not significantly different between the CMV seropositive individuals and CMV seronegative individuals in all the studied CD8+ T cell subsets (Fig. 1e).

\section{DNA methylation inversely correlates with protein expression}

To determine whether variations in DNA methylation at the described CpGs [20,36] are associated with changes 



Fig. 1 IFNY and PDI methylation in CMV seropositive and CMV seronegative healthy kidney donors. The percentage of DNA methylation of IFNY (a) and of PD1 (b) in CMV seronegative ( $n=15$; open bars) and CMV seropositive healthy donors $(n=15$; gray bars) in PBMCS (mean \pm SD) and stratified by gender (box and whiskers min to max). Gating strategy of the different CD8+ memory $T$ cell subsets in (c). The percentage of DNA methylation of IFNY (d) and of PDI (e) in CMV seropositive ( $n=5$; open bars) and CMV seronegative healthy donors ( $n=5$; gray bars) in cell sorted CD8+ T cell subsets; naïve, CD27+ memory, CD27- memory, and differentiated effector memory CD45RA+ (EMRA). Box and whiskers (min to max); ${ }^{*} p<0.05$ and ${ }^{* *} p<0.01$

in protein expression, we measured the expression of IFNY and PD1 in the different CD8+ T cell subsets (Fig. 2a). A clear-cut difference was observed between the naïve $\mathrm{CD} 8+\mathrm{T}$ cells compared to the memory CD8+ $\mathrm{T}$ cells where $14.6 \pm 16.4 \%$ (mean $\pm \mathrm{SD}$ ) of naïve $\mathrm{CD} 8+\mathrm{T}$ cells expressed IFNY versus $50.3 \pm 18.9 \%$ of the CD27+ memory, $52.6 \pm 20.6 \%$ of the CD27- memory and $66.1 \pm$ $19.8 \%$ of the EMRA CD8+ T cells expressed IFNy $(p<$ 0.0001; Fig. 2b). In parallel, a significantly lower percentage of naïve CD8+ T cells expressed PD1 compared to the memory $\mathrm{CD} 8+\mathrm{T}$ cell subsets (naïve $27.3 \pm 16.5 \%$, CD27+ memory $67.9 \pm 5.1 \%$, CD27- memory $68.4 \pm$ $12.2 \%$, and EMRA $51.4 \pm 20.1 ; p<0.0001$; Fig. 2 e). The highest percentage of IFN $\gamma$-expressing cells was found within the EMRA CD8+ T cells while the CD27+ and CD27- memory CD8+ $\mathrm{T}$ cell subsets contained the highest percentages of PD1-expressing cells. The DNA methylation of both $I F N \gamma$ and $P D 1$ demonstrated the opposite pattern with the highest percentage of methylation in naïve $\mathrm{CD} 8+\mathrm{T}$ cells. Naïve $\mathrm{CD} 8+\mathrm{T}$ cells were methylated for $55.2 \pm 18.3 \%$ at the IFN $\gamma$ locus and for $43.1 \pm 10.7 \%$ at the $P D 1$ locus. This methylation was significantly higher $(p<0.0001$ for both $I F N \gamma$ and PD1) compared to the different memory CD $8+\mathrm{T}$ cell subsets (Fig. 2c, f). This inverse relation between the DNA methylation and protein expression confirms the regulatory capacity of the studied CpGs (Fig. 2d, g).

\section{Variations in DNA methylation in kidney transplant recipients before transplantation}

Before kidney transplantation, the methylation of $I F N \gamma$ in CMV seronegative kidney recipients was comparable to the 


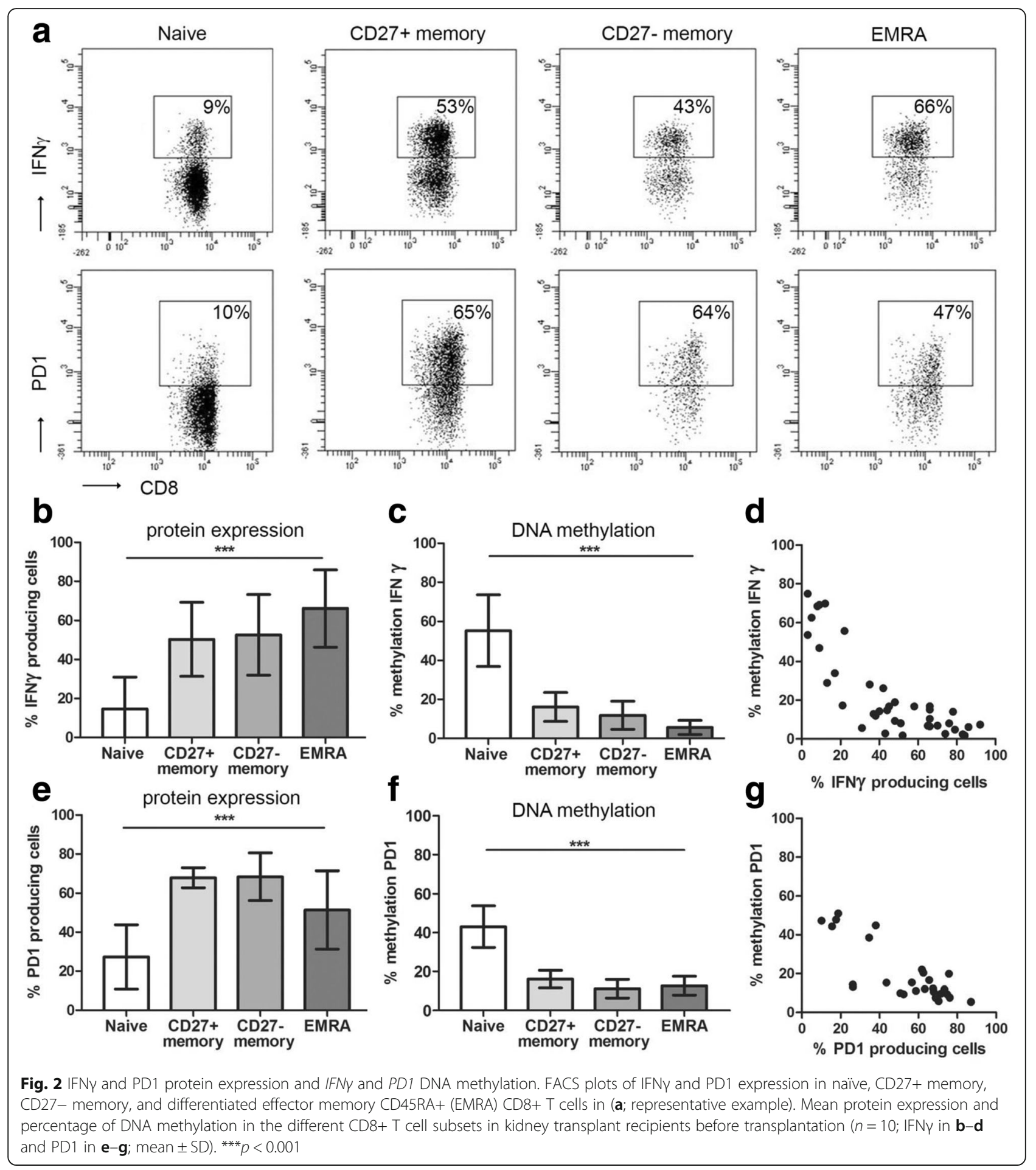

methylation levels in CMV seronegative healthy donors for naive, CD27+ memory, CD27- memory, and EMRA CD8+ T cells (Fig. 3a). The same pattern was seen for the methylation of PD1 (Fig. 3b). Subdividing the transplant recipients into the ones that went on to experience a rejection after transplantation, the rejectors and the non-rejectors, did not reveal any significant differences in methylation of
IFN $\gamma$ nor PD1, either between the two recipient groups or in comparison to the healthy donors (data not shown).

\section{Variations in DNA methylation in kidney transplant recipients after transplantation}

After kidney transplantation, the percentage of methylation of IFNy did not change significantly in the naïve, 

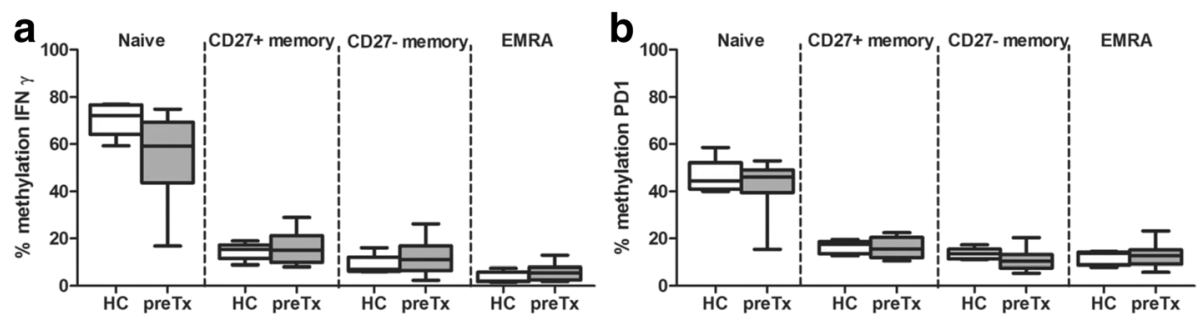

Fig. 3 IFNY and PDI methylation in healthy donors and kidney transplant recipients before transplantation. The percentage of DNA methylation of IFNY (a) and PDI (b) in healthy controls (HC; $n=5$; open bars) and kidney transplant recipients before transplantation (preTx; $n=10 ;$ gray bars) in cell sorted CD8+ T cell subsets; naïve, CD27+ memory, CD27- memory, and differentiated effector memory CD45RA+ (EMRA). Box and whiskers (min to max)

CD27+ memory, and CD27- memory CD8+ T cells during the first year after transplantation (Fig. $4 \mathrm{a}-\mathrm{C}$ ). In the EMRA CD8+ T cells, the methylation of IFN $\gamma$ was significantly higher at 3 months after transplantation compared to the methylation before transplantation irrespective of rejection and the subsequent antirejection therapy ( $p=0.01$; Fig. $4 \mathrm{~d})$. Focusing on rejection demonstrated that the methylation of IFN $\gamma$ was significantly higher at 3 months after transplantation in the rejectors $(14.3 \%$ versus $6.3 \%$ before transplantation; $p=$ 0.01 ) while the non-rejectors increased from 4.9 to $8.6 \%$ (not significant). Both rejectors and non-rejectors demonstrated elevated IFN $\gamma$ methylation levels in the EMRA $\mathrm{CD} 8+\mathrm{T}$ cells at 3 months after transplantation, but this increase in methylation was not significantly different between rejectors and non-rejectors $(p=0.3)$. At 1 year after transplantation, the methylation of IFN $\gamma$ was comparable to the levels measured before transplantation.

The methylation of PD1 did not change significantly in the naive $\mathrm{CD} 8+\mathrm{T}$ cells during the first year after transplantation (Fig. 4e). Irrespective of rejection, the methylation of $P D 1$ significantly increased during the first 3 months after transplantation in CD27+ memory CD8+ T cells with $7.2 \%(p=0.02)$, in CD27- memory CD8+ T cells with 7.9\% $(p=0.02)$, and in EMRA CD8+ T cells with $7.5 \%(p=0.002$; Fig. $4 f-h))$. Focusing on rejection demonstrated a more prominent increase in DNA methylation in the rejectors compared to the nonrejectors in all memory CD8+ $\mathrm{T}$ cell subsets $(\mathrm{CD} 27+$ memory: rejectors 27.8 versus $17.6 \%, p=0.02$ and nonrejectors 18.9 versus $14.6 \% p=0.3$; CD27- memory: rejectors 25.4 versus $11.4 \%, p=0.002$ and non-rejectors 12.7 versus $10.9 \%, p=0.6$; EMRA: rejectors 23.8 versus $13.2 \%$, $p=0.002$ and non-rejectors 16.5 versus $12.1 \%, p=0.2$; methylation at 3 months versus before transplantation, respectively). The increase in PD1 methylation in rejectors during the first 3 months after transplantation was not significantly different from the increase in PD1 methylation in non-rejectors in both the CD27+ memory CD8+ T cells $(p=0.3)$ and EMRA CD8+ T cells $(p=0.2)$. In the CD27- memory CD8+ $\mathrm{T}$ cells, the increase in PD1 methylation was significantly higher in the rejectors $(14 \%)$ compared to the non-rejectors $(1.9 \%, p=0.04)$. In parallel with the methylation of $I F N \gamma$, the methylation of PDI returned to normal levels at 1 year after transplantation.

\section{Discussion}

The clinical potential of DNA methylation in organ transplantation, either as diagnostic or prognostic biomarker or as therapeutic target has been proposed by many [5-8, 37, 38]. Nevertheless, this is the first study where DNA methylation of two selected genes, IFNy and PD1, was actually studied in CD8+ T cells in a small cohort of human kidney transplant recipients over time in relation to acute allograft rejection. Irrespective of rejection, we observed at 3 months after transplantation significantly elevated DNA methylation levels of $I F N \gamma$ in the differentiated EMRA CD8+ T cells, while the DNA methylation of PD1 was significantly higher in all CD8+ memory $\mathrm{T}$ cell subsets. This increase in IFN $\gamma$ methylation was not significantly different between rejectors and non-rejectors, while the increase in PD1 methylation was significantly higher in the rejectors in the CD27memory CD8+ $\mathrm{T}$ cells. In the other CD8+ memory $\mathrm{T}$ cells subsets (CD27+ memory and EMRA), the increase in DNA methylation of $P D 1$ was not significantly different between rejectors and non-rejectors.

Kidney transplantation will activate the recipient's immune system accompanied by an increase in cytokine production, including production of the pro-inflammatory IFNY $[35,39,40]$, and upregulation of PD1 expression [41]. As protein expression inversely correlates with DNA methylation levels at gene promoter sites, kidney transplantation induces demethylation of genes involved in immune activation. However, for both $I F N \gamma$ and $P D 1$, an increase in DNA methylation was observed in rejectors and non-rejectors in the first 3 months after transplantation, indicative for lower expression levels of IFN $\gamma$ and PD1. Likely, the expected demethylation is only detectable in the donor-antigen specific $\mathrm{T}$ cells. The low percentage of these cells within the selected CD8+ T cells explains why the expected decrease in methylation was not 

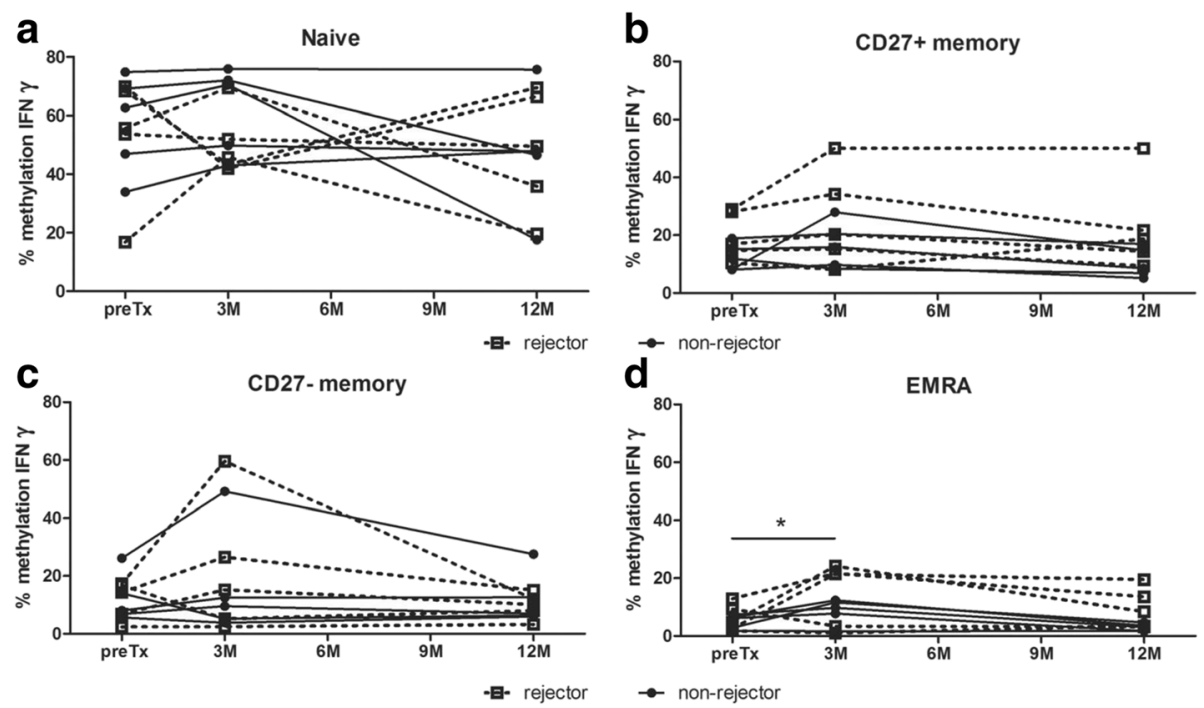

d

EMRA
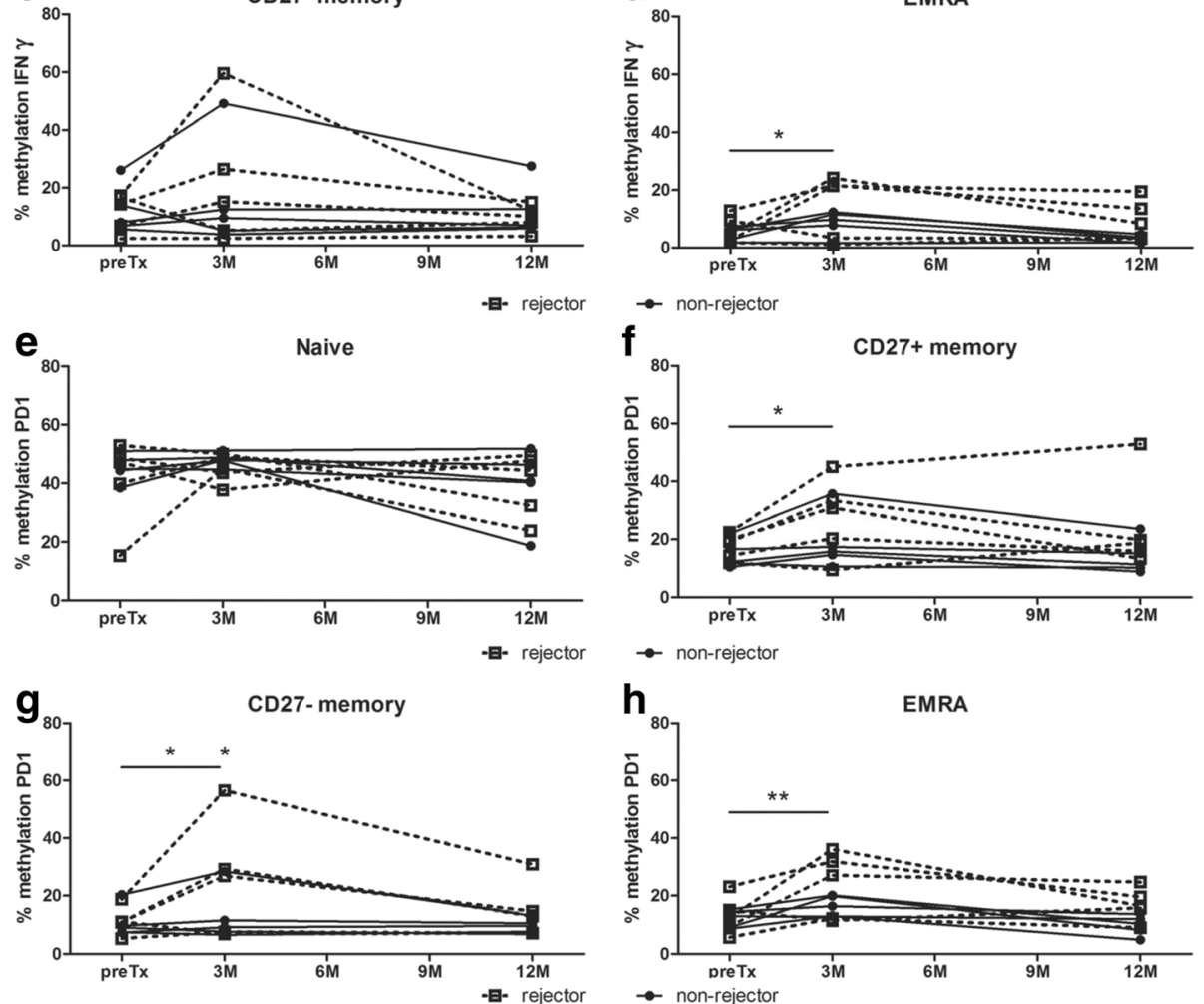

Fig. 4 IFNY and PDI methylation in kidney transplant recipients during the first year after transplantation. The percentage of DNA methylation of IFNY (a-d) and of PDI (e-h) in kidney transplant recipients before and 3 and 12 months after transplantation in cell sorted CD8+ T cell subsets; naïve $(\mathbf{a}, \mathbf{e}), C D 27+$ memory $(\mathbf{b}, \mathbf{f}), C D 27$ - memory $(\mathbf{c}, \mathbf{g})$, and differentiated effector memory CD45RA+ (EMRA; $\mathbf{d}, \mathbf{h}) .{ }^{*} p<0.05$ and ${ }^{* *} p<0.01$

observed. The observed increase in IFN $\gamma$ and PD1 DNA methylation most likely does not reflect the immune response against the foreign donor antigen but demonstrates a downregulation of the immune system achieved by the given immunosuppressive medication which nonspecifically block all $\mathrm{T}$ cell subsets. For example, the usage of prednisolone. In this study, prednisolone was tapered to $5 \mathrm{mg}$ at month 3 and thereafter completely withdrawn. At 1 year after transplantation, the DNA methylation levels returned to baseline.

In a clinical transplantation setting, it is impossible to measure the DNA methylation of either IFN $\gamma$ or PD1 just before rejection. Currently, rejection cannot be predicted as the moment of rejection strongly varies between individuals and therefore those samples are not available. Although the material was only available of a small number of patients, we had the unique opportunity to follow the same patients over time. Variations in DNA methylation are more profoundly found in the period after withdrawal of stress exposure (e.g., drugs) compared to the period during exposure $[42,43]$. Translation to the field of organ transplantation implies that after a rejection episode including anti-rejection therapy, rejectors would have more variations in DNA methylation compared to non-rejectors. However, this was not true for the methylation of either IFN $\gamma$ or $P D 1$ at 12 months after transplantation, indicating that allograft rejection has no imprinted effect on the DNA methylation of those immune genes.

Despite differences in immune activity of the distinct memory CD8 $+\mathrm{T}$ cell subsets, the variations in DNA methylation in either memory subset were comparable. 
The EMRA CD8+ $\mathrm{T}$ cells are potentially the most aggressive subtype with a strong cytolytic activity, while the CD27+ memory cells display weak cytolytic activity producing effector cytokines such as interleukin (IL) 2, IFN $\gamma$, tumor necrosis factor (TNF) $\alpha$, and IL4 $[44,45]$. The CD27- memory CD8+ T cells, which are functionally in between the CD27+ memory CD8+ T cells and the EMRA CD8+ T cells, represent the smallest subpopulation and it is unclear why specifically these cells demonstrated a significant difference in increase in methylation of $P D 1$ between rejectors and non-rejectors.

DNA methylation is adjustable by cues from the environment, e.g., viral infections $[20,24,46]$, though the exact cues and mechanisms remain largely unknown $[16,22,23]$. The uremic condition during chronic kidney disease (CKD) modifies DNA methylation profiles [47-49]. Although, before transplantation, we did not observe significant changes in the methylation of either PD1 or IFN $\gamma$ compared to agematched healthy donors. Either the previously observed effect on DNA methylation is gene specific and not applicable to IFNy and PD1 or the included transplant recipients here had less severe kidney disease compared to the CKD patients studied previously.

In contrast to previous observations where males demonstrated a significantly higher DNA methylation of IFN $\gamma$ compared to females [32], significant differences in DNA methylation between males and females were not observed. However, we observed a significantly lower \% of IFN $\mathrm{r}$ methylation in CMV seropositive healthy donors compared to CMV seronegative healthy donors. The effect of chronic CMV infection on DNA methylation is not documented yet, but the change of the composition of the $\mathrm{T}$ cell pool with a permanent increase in highly differentiated $\mathrm{T}$ cells with a more memory phenotype in CMV seropositive individuals [50] has been demonstrated repeatedly. Therefore, the lower \% of IFNY methylation in CMV seropositive individuals might be explained by the fact that memory $\mathrm{T}$ cells are less methylated at the IFN $\gamma$ locus (Fig. 2 and [12-14]). Nevertheless, also in selected CD8+ memory $\mathrm{T}$ cells, the methylation of $I F N \gamma$ was significantly lower in the CMV seropositive individuals (Fig. 1), indicating that CMV infection not only affects the composition of the $\mathrm{T}$ cell compartment but also induces a more aggressive $\mathrm{T}$ cell phenotype since demethylation is associated with an increased IFN $\gamma$ production.

Although we could not identify variations in DNA methylation of either IFNy or PD1 in CD8+ T cells which could either diagnose or predict allograft rejection after kidney transplantation, further research is needed to appreciate the clinical significance of variations in DNA methylation and other epigenetic mechanisms in kidney transplantation. Epigenetic biomarkers, mainly based on variations in DNA methylation, are well established in the diagnosis of cancer and are not only detectable in the affected tissue as well as in the urine or the peripheral blood [51, 52]. Currently, the application of epigenetic biomarkers is extended to other complex diseases such as autoimmune diseases [30, 53, 54]. The increasing knowledge on the epigenetic regulation of immune cells will contribute to our understanding of the epigenetic regulation of the complex anti-donor immune response after kidney transplantation. Epigenetic variations precede changes in protein expression and cell function and thereby represent an early indicator of clinical complications. Accordingly, a more comprehensive understanding of the epigenetic regulation of the antidonor immune response will learn whether variations in DNA methylation can serve as predictive, diagnostic, or prognostic markers. Moreover, since DNA methylation is influenced by environmental cues, it might serve as a target for therapeutic intervention.

A genome-wide approach instead of selected immunoregulatory genes are a good option for future research. Genome-wide analysis enables the identification of variations in DNA methylation in all promoter regions as well as other gene regions including intragenic and intergenic regions $[47,55,56]$. Since DNA methylation profiles are cell-type specific [57], selected cell subsets involved in the anti-donor immune response (e.g., CD4+ $T$ cell subsets, $B$ cells, and macrophages), or even better the donor-antigen specific cells, should be analyzed. Another interesting, though technically more challenging option, is to analyze variations in DNA methylation in graft-infiltrating T cells. As variations in DNA methylation occur specifically in donor-antigen specific cells which are more abundantly present in the graft compared to the circulation.

\section{Conclusions}

After kidney transplantation, the DNA methylation of the promoter of both $I F N \gamma$ and PD1 increases in the first 3 months and returns to baseline at 1 year after transplantation irrespective of rejection. These variations do not reflect the anti-donor immune response but are more likely the result of the transplantation procedure and the use of immunosuppressive medication.

\section{Methods \\ Study population}

Prior to the selection of kidney transplant recipients, we first determined whether cytomegalovirus (CMV) infection modulates DNA methylation of either IFN $\gamma$ or PD1. Peripheral blood mononuclear cells (PBMCs) of 15 CMV seropositive healthy donors (age 52 years, range 38-71; 5 males and 10 females) and 15 age-matched CMV seronegative healthy donors (age 52 years, range 44-59; 11 males and 4 females) were studied. Of these 
30 healthy donors in total, we selected 5 CMV seropositive and $5 \mathrm{CMV}$ seronegative age-matched individuals to study the methylation status in different CD8+ $\mathrm{T}$ cell subsets. Based on the significant decrease in DNA methylation of IFN $\gamma$ in CMV seropositive healthy donors, we included only CMV seronegative kidney transplant recipients who received their first kidney from a living donor. The DNA methylation of both $I F N \gamma$ and $P D 1$ was examined in different CD8+ T cell subsets in 5 recipients who developed a biopsy-proven acute cellular rejection within the first 3 months after transplantation (rejectors; Table 1) and 5 age-matched recipients who remained free from rejection the first year after transplantation (non-rejectors) and was compared to 5 agematched healthy donors (age 54 years, range 44-59). The different $\mathrm{CD} 8+\mathrm{T}$ cell subsets were analyzed at different time points; before transplantation and 3 and 12 months after transplantation. The selected CMV seronegative recipients all received a kidney from a CMV seronegative donor and received basiliximab as induction therapy. After transplantation, recipients received standard triple maintenance therapy consisting of prednisolone (tapered after 3 months), mycophenalate mofetil (MMF), and tacrolimus. Anti-rejection therapy consisted of methylprednisolone ( $1 \mathrm{~g}$ per day) on three consecutive days followed in some cases by anti-thymocyte globulin (ATG; $n=2)$ or alemtuzumab $(n=1)$.

\section{Isolation of peripheral blood mononuclear cells and CD8+ T cell subsets}

Peripheral blood mononuclear cells (PBMCs) were isolated from heparinized blood samples by density gradient centrifugation using standard Ficoll-Paque (GE Healthcare, Uppsala, Sweden) procedures. Since DNA methylation profiles are cell type specific [57], we examined naïve

Table 1 Clinical characteristics of kidney transplant recipients

\begin{tabular}{|c|c|c|}
\hline & Rejectors & Non-rejectors \\
\hline No. of subjects & 5 & 5 \\
\hline Age at transplantation (year) ${ }^{a}$ & $47(43-54)$ & $52(44-66)$ \\
\hline Gender (M/F) & $4 / 1$ & $5 / 0$ \\
\hline Serum creatinin $(\mu \mathrm{mol} / \mathrm{l})^{\mathrm{a}, \mathrm{b}}$ & $480(270-1484)$ & $532(374-682)$ \\
\hline \multicolumn{3}{|l|}{ Underlying kidney disease } \\
\hline HN/PKD/other & $3 / 1 / 1$ & $0 / 4 / 1$ \\
\hline \multicolumn{3}{|l|}{ Renal replacement therapy } \\
\hline HD/PD/pre-emptive & $1 / 2 / 2$ & $1 / 1 / 3$ \\
\hline Number of $\mathrm{HLA}-\mathrm{A} / \mathrm{B}$ mismatches ${ }^{c}$ & $2.2 \pm 0.4$ & $2.8 \pm 0.8$ \\
\hline Number of HLA-DR mismatches ${ }^{c}$ & $2.0 \pm 0$ & $1.0 \pm 0.7$ \\
\hline
\end{tabular}

$H N$ hypertensive nephropathy, $P K D$ polycystic kidney disease, $H D$ hemodialysis, $P D$ peritoneal dialysis

${ }^{\text {a } M e d i a n}$ with range

bBefore transplantation

${ }^{\mathrm{C}}$ Mean \pm SD (antigen unexperienced; CD27+CD45RA+) CD8+ T cells and memory (antigen experienced) $\mathrm{CD} 8+\mathrm{T}$ cells separately. The memory $\mathrm{CD} 8+\mathrm{T}$ cells were subdivided into the differentiated effector memory CD8+ $\mathrm{T}$ cells (EMRA: CD27-CD45RA+, with a strong cytolytic activity), CD27+ memory T cells (CD27+CD45RA-; with weak cytolytic potential), and CD27- memory T cells (CD27-CD45RA-; functionally in between CD27+ memory CD8+ T cells and EMRA CD8+ T cells) [44, 45]. The different CD8+ T cell subsets were isolated using cell sorting (BD FACSAria ${ }^{\text {mi }}$ II SORP, BD Biosciences, San Jose, CA, USA) with a mean purity of $96 \%$. Total PBMCs were stained with the following monoclonal antibodies: Brilliant Violet $510^{\mathrm{m}}$-labeled CD3 (Biolegend, San Diego, CA, USA), APC-Cy7-labeled CD8 (BD), PE-Cy7-labeled CD27 (eBioscience, San Diego), APC-labeled CD45RA (BD), and 7-aminoactinomycin $\mathrm{D}$ (7-AAD, $\mathrm{BD}$ ) for the exclusion of nonviable cells.

\section{Bisulfite conversion}

PBMCs and the FACS-sorted CD8+ T cell subsets were digested with proteinase $\mathrm{K}$ and treated with bisulfite using the EZ DNA Methylation-Direct Kit (Zymo Research from Base Clear Lab products, Leiden, The Netherlands), according to the manufacturer's instructions. During bisulfite treatment, unmethylated cytosines were converted into uracil, whereas methylated cytosines remained unchanged.

\section{PCR amplification and pyrosequencing}

The DNA methylation of the IFN $\gamma$ promoter was determined at two CpGs (CpG-186 and CpG-54) with transcription factor activity [36], and for PD1, eight previously described [20] CpG sites ranging between -914 and $-738 \mathrm{bp}$ from the start codon were studied (CpG-914, CpG-911, CpG-906, CpG-857, CpG-833, CpG-776, CpG-762, and CpG-738). Since the methylation status at adjacent CpGs is correlated [58], the mean $\%$ of methylation of either IFN $\gamma$ or PD1 was calculated. Primers for PCR and pyrosequencing were designed using PyroMark Assay Design 2.0 software (Qiagen, Venlo, The Netherlands; Table 2).

PCR amplifications were performed with the Pyromark PCR Kit from Qiagen with each primer in a concentration of $0.2 \mu \mathrm{M}$. The PCR conditions were $15 \mathrm{~min}$ at $95^{\circ}$ C, 45 cycles of $30 \mathrm{~s} 94{ }^{\circ} \mathrm{C}, 30 \mathrm{~s} 58^{\circ} \mathrm{C}$ for $I F N \gamma$ and $56^{\circ} \mathrm{C}$ for PD1 and $30 \mathrm{~s} 72{ }^{\circ} \mathrm{C}$ followed by $10 \mathrm{~min}$ at $72{ }^{\circ} \mathrm{C}$ and on hold at $21{ }^{\circ} \mathrm{C}$. After visualization of the appropriately sized PCR product on a $1 \%$ agarose gel, the PCR product was sequenced using a PyroMark Q24 pyrosequencer (Qiagen) with the following minor revisions to the manufacturer's instructions: to immobilize the PCR product, $1 \mu$ l Streptavidin Sepharose High Performance Beads (GE Healtcare) were used per sequence reaction and 
Table 2 Primers for PCR amplification and pyrosequencing

\begin{tabular}{|c|c|c|}
\hline Gene & Primers & CpGs \\
\hline \multirow[t]{4}{*}{ IFNY } & F: 5'-ATGGTATAGGTGGGTATAATGG-3' & \\
\hline & R: 5'-biotin-CAATATACTACACCTCCTCTAACTAC-3' & \\
\hline & S: 5'-GGTGGGTATAATGGG-3' & CpG-186 \\
\hline & S: 5'-ATTATTTTATTTTAAAAAATTTGTG-3' & CpG-54 \\
\hline \multirow[t]{5}{*}{ PD1 } & F: 5'-AGTATAGAATATAAGGAGATAAGTAAGT-3' & \\
\hline & R: 5'-biotin-CCATAACCACAATTCCAAATCTTT-3' & \\
\hline & S: 5'-AGAATATAAGGAGATAAGTAAGTT'-3' & CpG-914, CpG-911, CpG-906 \\
\hline & S: 5'-GGATTTTTGAATTATTTTATTTTG'-3' & CpG-857, CpG-833 \\
\hline & S: 5'-TTAGTTTATAAGTAAGTTITG-3' & CpG-776, CpG-762, CpG-738 \\
\hline
\end{tabular}

$F$ forward primer, $R$ reverse primer, $S$ sequencing primer, $C p G s$ cytosine phosphate guanine sites

annealing of the sequence primers was done for $3 \mathrm{~min}$ at $80{ }^{\circ} \mathrm{C}$. The bisulfite conversion and the subsequent PCR amplification and pyrosequencing were performed in duplicate. Human low and high methylated DNA from EpigenDx (Hopkinton, MA, USA) were used as controls.

\section{IFN $\gamma$ and PD1 protein expression}

To determine IFN $\gamma$ and PD1 protein production by the different CD8+ T cell subsets, total PBMCs were either not stimulated or stimulated in the presence of $1 \mu \mathrm{g} / \mathrm{ml}$ Brefeldin A (GolgiPlug; BD Biosciences) with PMA (50 ng/ml, Sigma-Aldrich, St. Louis, MO, USA) and ionomycin $\left(1 \mu \mathrm{g} / \mathrm{ml}\right.$, Sigma-Aldrich) for $4 \mathrm{~h}$ at $37^{\circ} \mathrm{C}$ in $5 \% \mathrm{CO}_{2}$. For IFNy, cells were stained for $30 \mathrm{~min}$ for the following surface markers: Brilliant Violet $510^{\mathrm{mm}}$-labeled CD3 (Biolegend), APC-Cy7-labeled CD8 (BD Biosciences), PE-Cy7-labeled CD27 (eBioscience), APC-labeled CD45RA (BD Biosciences), and 7-amino-actinomycin D (7-AAD, BD Biosciences), fixed, permeabilized, and stained with FITC-labeled IFNY (BD Biosciences) for $30 \mathrm{~min}$. Frequencies of IFN $\gamma$-producing $\mathrm{CD} 8+\mathrm{T}$ cell subsets were corrected for background determined with the unstimulated condition. For PD1, cells were stained with the previously described surface markers while PElabeled PD1 (Biolegend) was added. For PD1 expression, a Fluorescence Minus One (FMO) was used to correct for background staining. Samples were measured on the FACSCanto II (BD) and analyzed using FACSDiva software version 6.1.2. (BD).

\section{Statistical analysis}

To identify differences between groups, the unpaired $t$ test, Mann-Whitney $U$ test, and ANOVA were used as appropriate. To determine differences after kidney transplantation over time between rejectors and nonrejectors, we used multilevel analysis with the percentage of DNA methylation as outcome. Predictors were different individuals (rejectors and non-rejectors), time also as categorical predictor (levels 0 (before transplantation), 3 and 12 months after transplantation), and individuals as random intercept. Each model was applied for the four different cell types studied; naïve, CD27+ memory, CD27- memory, and EMRA CD8+ T cell subsets. Afterwards, we added models with interaction between type of individual and time. The first model describes the same pattern over time for both rejectors and non-rejectors while the second one enables to estimate and test different trends in time for rejectors and non-rejectors. The estimates and standard errors were transformed to Cl's and $p$ values. We used the package $\mathrm{R}$ version 3.1 .2 and libraries lmer and lmerTest. A $p$ value of $<0.05$ was considered statistically significant.

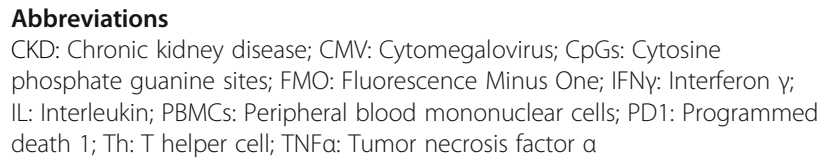

\section{Acknowledgements}

The authors would like to thank P.M. van Koetsveld for his support in the development in the pyrosequencing assays and R. Kraaijeveld and W. Verschoor for their assistance in cell sorting. The purchase of the PyroMark Q24 pyrosequencer was financially supported by Erasmus MC Vriendenfonds.

\section{Funding}

Not applicable.

\section{Availability of data and materials}

Methylation data are available on request.

\begin{abstract}
Authors' contributions
KB contributed to design, analysis, and interpretation of the results and writing of the manuscript. LEAW developed analytical tools and performed the experiments. FSP contributed to data interpretation and writing of the manuscript. DAH included patients and reviewed the manuscript. LJH provided analytical tools. MGH reviewed the manuscript. CWNL performed the statistical multilevel analysis. CCB contributed to design, data interpretation, and writing of the manuscript. All authors read and approved the final manuscript.
\end{abstract}

Competing interests

The authors declare that they have no competing interests. 


\section{Consent for publication}

Not applicable.

\section{Ethics approval and consent to participate}

The study was approved by the local ethical committee (METC 2010-080).

\section{Author details}

'Department of Internal Medicine, Section Nephrology and Transplantation, Erasmus MC, University Medical Center Rotterdam, Room Na520, P.O. Box 20403000 CA Rotterdam, The Netherlands. ${ }^{2}$ Department of Internal Medicine, Section Endocrinology, University Medical Center Rotterdam, Rotterdam, The Netherlands. ${ }^{3}$ Department of Public Health, Erasmus MC, University Medical Center Rotterdam, Rotterdam, The Netherlands.

\section{Received: 5 July 2016 Accepted: 8 November 2016}

\section{Published online: 16 November 2016}

\section{References}

1. Abecassis M, Bartlett ST, Collins AJ, Davis CL, Delmonico FL, Friedewald JJ, et al. Kidney transplantation as primary therapy for end-stage renal disease: a National Kidney Foundation/Kidney Disease Outcomes Quality Initiative (NKF/KDOQITM) conference. Clin J Am Soc Nephrol. 2008;3:471-80.

2. Matas AJ, Smith JM, Skeans MA, Lamb KE, Gustafson SK, Samana CJ, et al. OPTN/SRTR 2011 annual data report: kidney. Am J Transplant. 2013:13 Suppl 1:11-46.

3. Roedder S, Vitalone M, Khatri P, Sarwal MM. Biomarkers in solid organ transplantation: establishing personalized transplantation medicine. Genome Med. 2011;3:37.

4. Reeve J, Einecke G, Mengel M, Sis B, Kayser N, Kaplan B, et al. Diagnosing rejection in renal transplants: a comparison of molecular- and histopathology-based approaches. Am J Transplant. 2009;9:1802-10.

5. Suarez-Alvarez B, Baragano Raneros A, Ortega F, Lopez-Larrea C. Epigenetic modulation of the immune function: a potential target for tolerance. Epigenetics. 2013;8:694-702.

6. LaMere SA, Komori HK, Salomon DR. New opportunities for organ transplantation research: epigenetics is likely to be an important determinant of the host immune response. Epigenomics. 2013;5:243-6.

7. McCaughan JA, McKnight AJ, Courtney AE, Maxwell AP. Epigenetics: time to translate into transplantation. Transplantation. 2012;94:1-7.

8. Mas VR, Le TH, Maluf DG. Epigenetics in kidney transplantation: current evidence, predictions, and future research directions. Transplantation. 2016; 100:23-38.

9. Najafian N, Salama AD, Fedoseyeva EV, Benichou G, Sayegh MH. Enzyme-linked immunosorbent spot assay analysis of peripheral blood lymphocyte reactivity to donor HLA-DR peptides: potential novel assay for prediction of outcomes for renal transplant recipients. J Am Soc Nephrol. 2002;13:252-9.

10. Nickel P, Presber F, Bold G, Biti D, Schonemann C, Tullius SG, et al. Enzymelinked immunosorbent spot assay for donor-reactive interferon-gammaproducing cells identifies T-cell presensitization and correlates with graft function at 6 and 12 months in renal-transplant recipients. Transplantation. 2004:78:1640-6.

11. Brunet M, Millan Lopez O, Lopez-Hoyos M. T-cell cytokines as predictive markers of the risk of allograft rejection. Ther Drug Monit. 2016;38 Suppl 1:S21-8.

12. Gray SM, Kaech SM, Staron MM. The interface between transcriptional and epigenetic control of effector and memory CD8(+) T-cell differentiation. Immunol Rev. 2014;261:157-68.

13. Dong J, Chang HD, Ivascu C, Qian Y, Rezai S, Okhrimenko A, et al. Loss of methylation at the IFNG promoter and CNS-1 is associated with the development of functional IFN-gamma memory in human CD4(+) T lymphocytes. Eur J Immunol. 2013;43:793-804.

14. Shnyreva M, Weaver WM, Blanchette M, Taylor SL, Tompa M, Fitzpatrick DR, et al. Evolutionarily conserved sequence elements that positively regulate IFN-gamma expression in T cells. Proc Natl Acad Sci U S A. 2004;101:12622-7.

15. White GP, Hollams EM, Yerkovich ST, Bosco A, Holt BJ, Bassami MR, et al. CpG methylation patterns in the IFNgamma promoter in naive T cells: variations during Th1 and Th2 differentiation and between atopics and non-atopics. Pediatr Allergy Immunol. 2006;17:557-64.

16. Suarez-Alvarez B, Rodriguez RM, Fraga MF, Lopez-Larrea C. DNA methylation: a promising landscape for immune system-related diseases. Trends Genet. 2012;28:506-14.
17. Aune TM, Collins PL, Collier SP, Henderson MA, Chang S. Epigenetic activation and silencing of the gene that encodes IFN-gamma. Front Immunol. 2013;4:112.

18. Riella LV, Paterson AM, Sharpe AH, Chandraker A. Role of the PD-1 pathway in the immune response. Am J Transplant. 2012;12:2575-87.

19. Francisco LM, Salinas VH, Brown KE, Vanguri VK, Freeman GJ, Kuchroo VK, et al. PD-L1 regulates the development, maintenance, and function of induced regulatory T cells. J Exp Med. 2009;206:3015-29.

20. Youngblood B, Oestreich KJ, Ha SJ, Duraiswamy J, Akondy RS, West EE, et al. Chronic virus infection enforces demethylation of the locus that encodes PD-1 in antigen-specific CD8(+) T cells. Immunity. 2011;35:400-12.

21. Law JA, Jacobsen SE. Establishing, maintaining and modifying DNA methylation patterns in plants and animals. Nat Rev Genet. 2010;11:204-20.

22. Heijmans BT, Tobi EW, Stein AD, Putter H, Blauw GJ, Susser ES, et al. Persistent epigenetic differences associated with prenatal exposure to famine in humans. Proc Natl Acad Sci U S A. 2008;105:17046-9.

23. Feil R, Fraga MF. Epigenetics and the environment: emerging patterns and implications. Nat Rev Genet. 2011;13:97-109.

24. Adhya D, Basu A. Epigenetic modulation of host: new insights into immune evasion by viruses. J Biosci. 2010;35:647-63.

25. Esteller M. Epigenetics in cancer. N Engl J Med. 2008;358:1148-59.

26. Portela A, Esteller M. Epigenetic modifications and human disease. Nat Biotechnol. 2010;28:1057-68.

27. Heyn H, Esteller M. DNA methylation profiling in the clinic: applications and challenges. Nat Rev Genet. 2012;13:679-92.

28. Stenvinkel P, Karimi M, Johansson S, Axelsson J, Suliman M, Lindholm B, et al. Impact of inflammation on epigenetic DNA methylation-a novel risk factor for cardiovascular disease? J Intern Med. 2007;261:488-99.

29. Ingrosso D, Cimmino A, Perna AF, Masella L, De Santo NG, De Bonis ML, et al. Folate treatment and unbalanced methylation and changes of allelic expression induced by hyperhomocysteinaemia in patients with uraemia. Lancet. 2003;361:1693-9.

30. Glossop JR, Emes RD, Nixon NB, Haworth KE, Packham JC, Dawes PT, et al. Genome-wide DNA methylation profiling in rheumatoid arthritis identifies disease-associated methylation changes that are distinct to individual T- and B-ymphocyte populations. Epigenetics. 2014;9:1228-37.

31. Berni Canani R, Paparo L, Nocerino R, Cosenza L, Pezzella V, Di Costanzo M, et al. Differences in DNA methylation profile of Th1 and Th2 cytokine genes are associated with tolerance acquisition in children with lgE-mediated cow's milk allergy. Clin Epigenetics. 2015;7:38.

32. Lovinsky-Desir S, Ridder R, Torrone D, Maher C, Narula S, Scheuerman M, et al. DNA methylation of the allergy regulatory gene interferon gamma varies by age, sex, and tissue type in asthmatics. Clin Epigenetics. 2014;6:9.

33. Betjes MG, Meijers RW, de Wit EA, Weimar W, Litjens NH. Terminally differentiated CD8+ Temra cells are associated with the risk for acute kidney allograft rejection. Transplantation. 2012;94:63-9.

34. San Segundo D, San Segundo D. Increased numbers of circulating CD8 effector memory $T$ cells before transplantation enhance the risk of acute rejection in lung transplant recipients. PLoS One. 2013;8:e80601.

35. Yap M, Brouard S, Pecqueur C, Degauque N. Targeting CD8 T-cell metabolism in transplantation. Front Immunol. 2015;6:547.

36. White GP, Watt PM, Holt BJ, Holt PG. Differential patterns of methylation of the IFN-gamma promoter at $\mathrm{CpG}$ and non-CpG sites underlie differences in IFN-gamma gene expression between human neonatal and adult CD45RO- T cells. J Immunol. 2002;168:2820-7.

37. Heylen L, Thienpont B, Naesens M, Lambrechts D, Sprangers B. The emerging role of DNA methylation in kidney transplantation: a perspective. Am J Transplant. 2016.

38. Peters FS, Manintveld OC, Betjes MG, Baan CC, Boer K. Clinical potential of DNA methylation in organ transplantation. J Heart Lung Transplant. 2016;35(7):843-50

39. Robertson H, Wheeler J, Kirby JA, Morley AR. Renal allograft rejection -in situ demonstration of cytotoxic intratubular cells. Transplantation. 1996;61:1546-9.

40. Steinmuller D. Which T, cells mediate allograft rejection? Transplantation. 1985;40:229-33.

41. Keir ME, Butte MJ, Freeman GJ, Sharpe AH. PD-1 and its ligands in tolerance and immunity. Annu Rev Immunol. 2008;26:677-704.

42. Massart R, Barnea R, Dikshtein Y, Suderman M, Meir O, Hallett M, et al. Role of DNA methylation in the nucleus accumbens in incubation of cocaine craving. J Neurosci. 2015;35:8042-58.

43. Faulk C, Dolinoy DC. Timing is everything: the when and how of environmentally induced changes in the epigenome of animals. Epigenetics. 2011;6:791-7. 
44. Hamann D, Baars PA, Rep MH, Hooibrink B, Kerkhof-Garde SR, Klein MR, et al. Phenotypic and functional separation of memory and effector human CD8+ T cells. J Exp Med. 1997;186:1407-18.

45. Appay V, van Lier RA, Sallusto F, Roederer M. Phenotype and function of human T lymphocyte subsets: consensus and issues. Cytometry A. 2008;73: 975-83.

46. Youngblood B, Noto A, Porichis F, Akondy RS, Ndhlovu ZM, Austin JW, et al. Cutting edge: Prolonged exposure to HIV reinforces a poised epigenetic program for PD-1 expression in virus-specific CD8 T cells. J Immunol. 2013; 191:540-4.

47. Smyth LJ, McKay GJ, Maxwell AP, McKnight AJ. DNA hypermethylation and DNA hypomethylation is present at different loci in chronic kidney disease. Epigenetics. 2014;9:366-76.

48. Zawada AM, Rogacev KS, Hummel B, Grun OS, Friedrich A, Rotter B, et al. SuperTAG methylation-specific digital karyotyping reveals uremia-induced epigenetic dysregulation of atherosclerosis-related genes. Circ Cardiovasc Genet. 2012:5:611-20.

49. Ko YA, Mohtat D, Suzuki M, Park AS, Izquierdo MC, Han SY, et al. Cytosine methylation changes in enhancer regions of core pro-fibrotic genes characterize kidney fibrosis development. Genome Biol. 2013;14:R108.

50. Kuijpers TW, Vossen MT, Gent MR, Davin JC, Roos MT, Wertheim-van Dillen PM, et al. Frequencies of circulating cytolytic, CD45RA+CD27-, CD8+ T lymphocytes depend on infection with CMV. J Immunol. 2003;170:4342-8.

51. Mlcochova H, Hezova R, Stanik M, Slaby O. Urine microRNAs as potentia noninvasive biomarkers in urologic cancers. Urol Oncol. 2014;32:41. e1-9.

52. Li L, Choi JY, Lee KM, Sung H, Park SK, Oze I, et al. DNA methylation in peripheral blood: a potential biomarker for cancer molecular epidemiology. J Epidemiol. 2012;22:384-94.

53. Sun B, Hu L, Luo ZY, Chen XP, Zhou HH, Zhang W. DNA methylation perspectives in the pathogenesis of autoimmune diseases. Clin Immunol. 2016;164:21-7.

54. Aslani S, Mahmoudi M, Karami J, Jamshidi AR, Malekshahi Z, Nicknam MH. Epigenetic alterations underlying autoimmune diseases. Autoimmunity. 2016;49:69-83

55. Deaton AM, Webb S, Kerr AR, Illingworth RS, Guy J, Andrews R, et al. Cell type-specific DNA methylation at intragenic CpG islands in the immune system. Genome Res. 2011;21:1074-86.

56. Maunakea AK, Nagarajan RP, Bilenky M, Ballinger TJ, D'Souza C, Fouse SD, et al. Conserved role of intragenic DNA methylation in regulating alternative promoters. Nature. 2010;466:253-7.

57. Adalsteinsson BT, Gudnason H, Aspelund T, Harris TB, Launer L, Eiriksdottir $\mathrm{G}$, et al. Heterogeneity in white blood cells has potential to confound DNA methylation measurements. PLoS One. 2012;7, e46705.

58. Shoemaker R, Deng J, Wang W, Zhang K. Allele-specific methylation is prevalent and is contributed by $\mathrm{CpG}-\mathrm{SNPS}$ in the human genome. Genome Res. 2010;20:883-9.

\section{Submit your next manuscript to BioMed Central and we will help you at every step:}

- We accept pre-submission inquiries

- Our selector tool helps you to find the most relevant journal

- We provide round the clock customer support

- Convenient online submission

- Thorough peer review

- Inclusion in PubMed and all major indexing services

- Maximum visibility for your research

Submit your manuscript at www.biomedcentral.com/submit

) Biomed Central 